\title{
Eddy tracking south of Canary Islands using satellite observations
}

\author{
A. Tejera-Cruz ${ }^{\mathrm{a}}$, O. Bergasa-López ${ }^{\mathrm{a}}$, L. García-Weil ${ }^{\mathrm{a}}$, A. Luque-Sölheim ${ }^{\mathrm{a}}$ \\ ${ }^{a}$ Physics Department, University of Las Palmas de Gran Canaria; Campus de Tafira, 35017, Las \\ Palmas. España.
}

\begin{abstract}
Eddies generated by the Canary Current south of Canary Islands when the flow passes through the archipelago define a high mesoscale variability of the sea level downstream of the islands. Evidence of zonal propagation of perturbations of sea surface heights was observed by generating longitude-time plots. Hovmöller diagrams of the altimetric data for 1997 and 1998 at $27^{\circ} \mathrm{N}$ (south of Cape Jubi), $26^{\circ} \mathrm{N}$ (Cape Bojador) and $25^{\circ} \mathrm{N}$ (south of Cape Bojador) are analysed. Both cyclones and anticyclones were observed in the satellite data as anomalies originating south of Gran Canaria or Tenerife islands and moving southward of Gomera and El Hierro islands. The sea level variability associated with these mesoscale features, has the highest intensity during sunmer and autumn, when Trade winds and incident currents are stronger. An anticyclonic eddy observed in December 1997 is described on the basis of sea level anomalies deduced from TOPEX/POSEIDON and ERS altimetry and sea surface temperature data. This mesoscale oceanographic feature was tracked approximately 3 months (October-January), decreasing at the sea surface elevation from $25 \mathrm{~cm}$ registered at the end of November at $26.5^{\circ} \mathrm{N}$ to $15 \mathrm{~cm}$ in January. During this period the vortex is moved southwest at $1.7 \mathrm{~km} /$ day. Comparisons between sea level anomalies from altimetry and sea surface temperature images from AVHRR agree that the eddy was moved and modified its characteristics during this period.
\end{abstract}

Keywords: Sea level anomaly, altimeter, anticyclonic and cyclonic eddies, Canary Current.

\section{INTRODUCTION}

In the last decade one of the most promising means of acquiring synoptic information on mesoscale oceanographic features around Canary Archipelago is by remotely sensed data (Hernández-Guerra et al., 1993; Tejera et al., 1996; Garcia, 1998; Barton et al., 1998; Tejera et al., 2002). The geographical situation of Canary Islands between cool, nutrient-rich upwelled water from the Northwesl African coastal upwelling region and warmer, nutrient-poor offshore water means that this region is of considerable oceanographic interest. Besides, the archipelago, consisting of seven islands located at $28^{\circ} \mathrm{N}$ approximately, acts as an obstacle to the Canary Current, which flows NNE to SSW through the islands, and provide a source of mesoscale activity. Sea surface temperature and chlorophyll scenes from satellite passive sensors have revealed anlicyclonic (warm-core) and cyclonic (cold-core) eddies found at south of the islands. Different works using mainly hydrographic data have reported these mesoscale phenomena associated at the south of Gran Canaria island (Aristegui et al., 1994; Basterretxea et al., 2002). From those previous works the size of the eddies have been determinated about $50 \mathrm{~km}$ diameter and they extend several hundred metres in depth. Antioyclonic eddies have been shown as predominant features in the mesoscale dynamics in recent studies which present big size $(\sim 150 \mathrm{~km})$ (GarctaWeil et al., 2003)

Radar altimeter data have been used in this region to detect oceanographic mesoscale features (Tejera et al, 1997). Basically, the radar measures the height between the satellite and the surface sea. From the original measurement, the oceanographic signal, sea level anomalies, can be obtained after to apply some instrumental and geophysical correction to the data. Eddies have marked effects on the sea surface height appearing as elevations (anticyclonic ring) or depressions (cyclonic ring) relative surrounding waters. Therefore, this technique offers an alternative tracking method because is not affected by the cloud cover. Besides the great spatial and temporal coverage of the remote sensing observations respect to hydrographic data help us to analyze some aspects related to the formation and evolution of the eddies, mainly those centred, initially at south of the Tenerife and Gran Canaria islands $\left(\sim 27^{\circ} \mathrm{N}\right)$, and located rather southward from that position $\left(\sim 24^{\circ} \mathrm{N}\right)$. 
In the present work we have studied eddies propagation at south of the archipelago using the radar altimeters on board of ERS and TOPEX/Poseidon satellite from January of 1997 to December of 1998 . We have also used sea surface temperature images from AVHRR sensor. Initially sea level anomaly maps have been selected to detect eddies and they have been located also using SST scenes when they coincide temporally. Then, longitude-latitude plots have been made to provide observational evidence about the temporal evolution in the study area. The following section describes the data and methodology employed. Next, we show how eddies are represented in the altimetric sea surface height anomalies and sea surface temperature scenes. Finally, we summarize and discuss the findings of this study.

\section{DATA USED}

ERS-2 and TOPEX/POSEIDON sea level anomalies (SLA) data from January 1997 to December 1998 were processed for this work. The used data are combined TOPEX/Poseidon and ERS altimetry data available from the Archiving, Validation and Interpretation of Satellite Oceanographic (AVISO, 1998). SLA data were produced by the Collecte Localization Satellite (CLS), and the standard sets of geophysical corrections, environmental perturbations, tides and the inverse barometer influences were applied by CLS. The heights were generated from those files using the conventional repeat-track method (AVISO, 1998). The maps are formed from a combination of TOPEX/Poseidon 10-day repeat orbit and ERS 35 -day repeat orbit data objectively analyzed on to a $0.5^{\circ}$ resolution map grid. The SLA data were gridded onto 15 days, $0.5^{\circ}$ resolution maps using the successive correction method and the successive radii of influence are $200 \mathrm{~km}, 150 \mathrm{~km}$ and $100 \mathrm{~km}$ (Heywood, et al, 1994 Tejera, et al, 2002). The satellite tracks in the study area shown in Fig. 1. Using combined data avoids the persistent between track gaps that present in the TOPEX/Poseidon data alone.

AVHRR images from NOAA thermal infrared channels are also used corresponding to $1997 \mathrm{and} 1998$ year. It have been captured by the receiving station belonging to the Servicio de Ecología Asistido por Satélite (SeaS-Canarias) at the Universidad de Las Palmas de Gran Canaria. The raw data were processed to channel four brightness temperature and sea surface temperature (SST) scenes. Then geometric distortions of satellite images were renoved and they were mapped to the same Mercartor projection. In this work brightness temperature images have been showed because the mesoscale features are better observed.

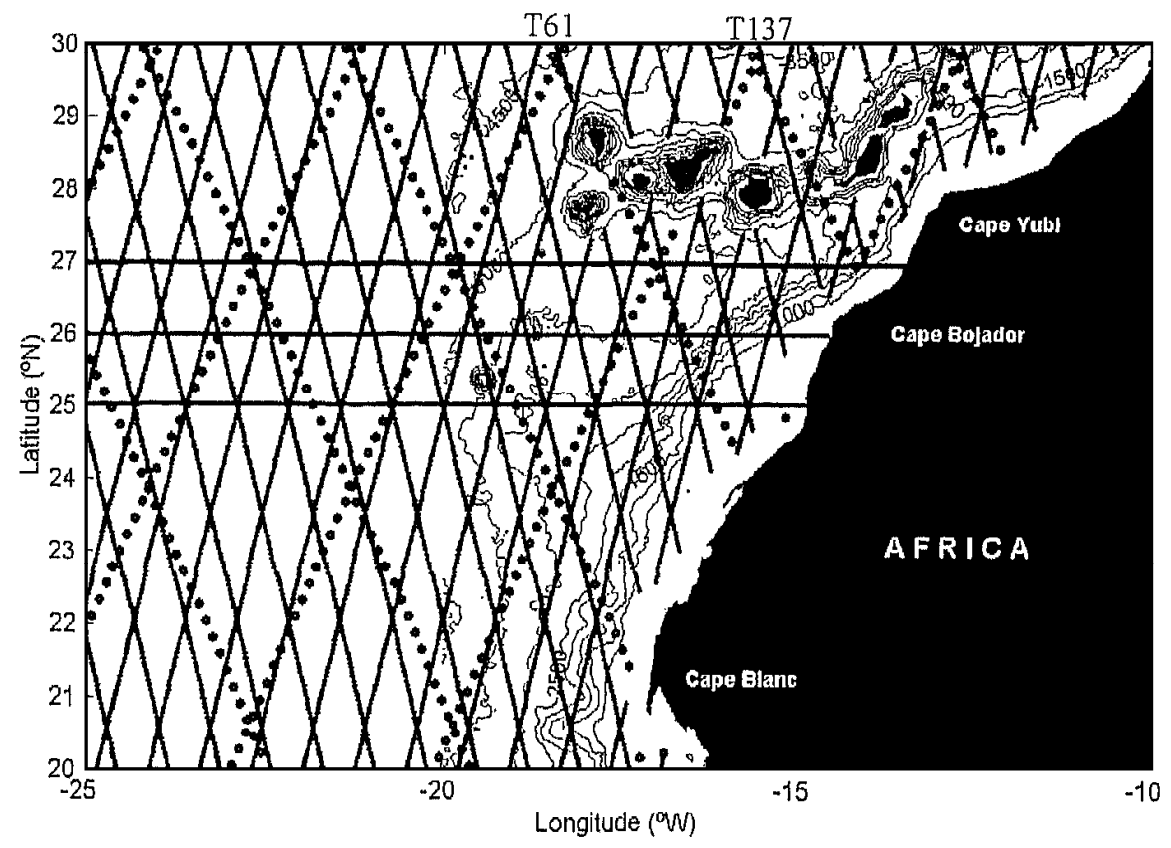

Figure 1.- The study are showing the ERS (solid line) and TOPEX/Poseidon tracks (dash line). From left to right the islands are: El Hierro, La Palma, Gomera, Tenerife, Gran Canaria, Fuerteventura y Lanzarote. 


\section{RESULTS}

Altimeter SLA maps from ERS and TOPEX/Poseidon combined data are shown in Fig. 2. In general the highest mesoscale activity seems to be centred in October (Fig. 2a), November (Fig. 2b) and December (Fig. 2c). The positive values greater than $20 \mathrm{~cm}$ are located north of La Palma, south Tenerife and southwest of El Hierro islands and they are corresponded to anticyclonic eddies downstream of the islands. These maps show a richness of eddies in the studied region. An example of that we have focused our attention in the evolution of the anticyclone marked by $\mathrm{AC}$, and using at the same time altimeter data and sea surface temperature images.
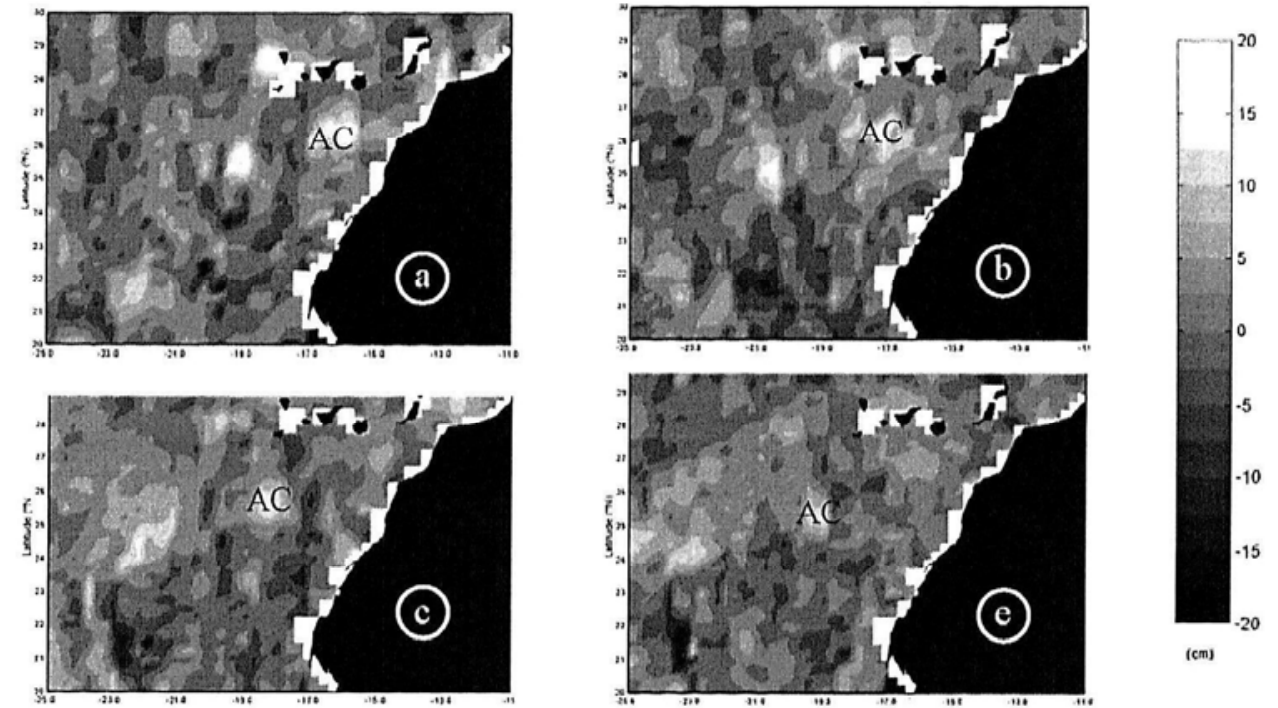

(cm)

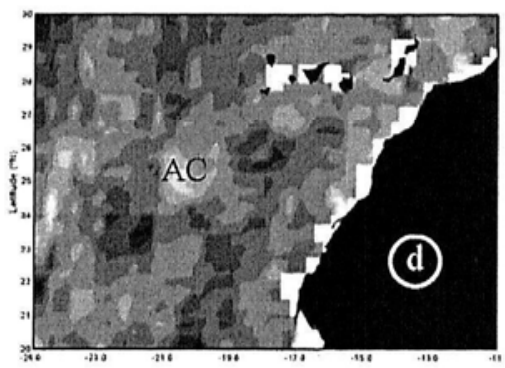

Figure 2.- Sea level anomaly maps from ERS and TOPEX/Poseidon altimeter data.

The anticyclone AC initially appears at south of Tenerife in the altimetric signal. The development of this feature indicates a slow movement at southwest with a decrease in its size and also in intensity of the sea level variation. The final position identified in the data is at $25^{\circ} \mathrm{N}$ and $20^{\circ} \mathrm{W}$. The anticyclone south of $27^{\circ} \mathrm{N}(\mathrm{AC})$ was also observed in sea surface temperature images (Fig. 3); in the scenes the warmer water associated with anticyclonic vortex are showed in black colour. In spite of the cloud covers in December and January it was possible to have some cloud free scenes south of the archipelago. Anticyclone AC is detected 1 December directly to the south of Gomera island (Fig. 3a). It continued to move southwest to $26^{\circ} \mathrm{N}$ and was also presented fifteen days later in SST signal (Fig. 3b and 3c). This intense feature persisted and it could be recognized in January 1998 (Fig. 3d). 

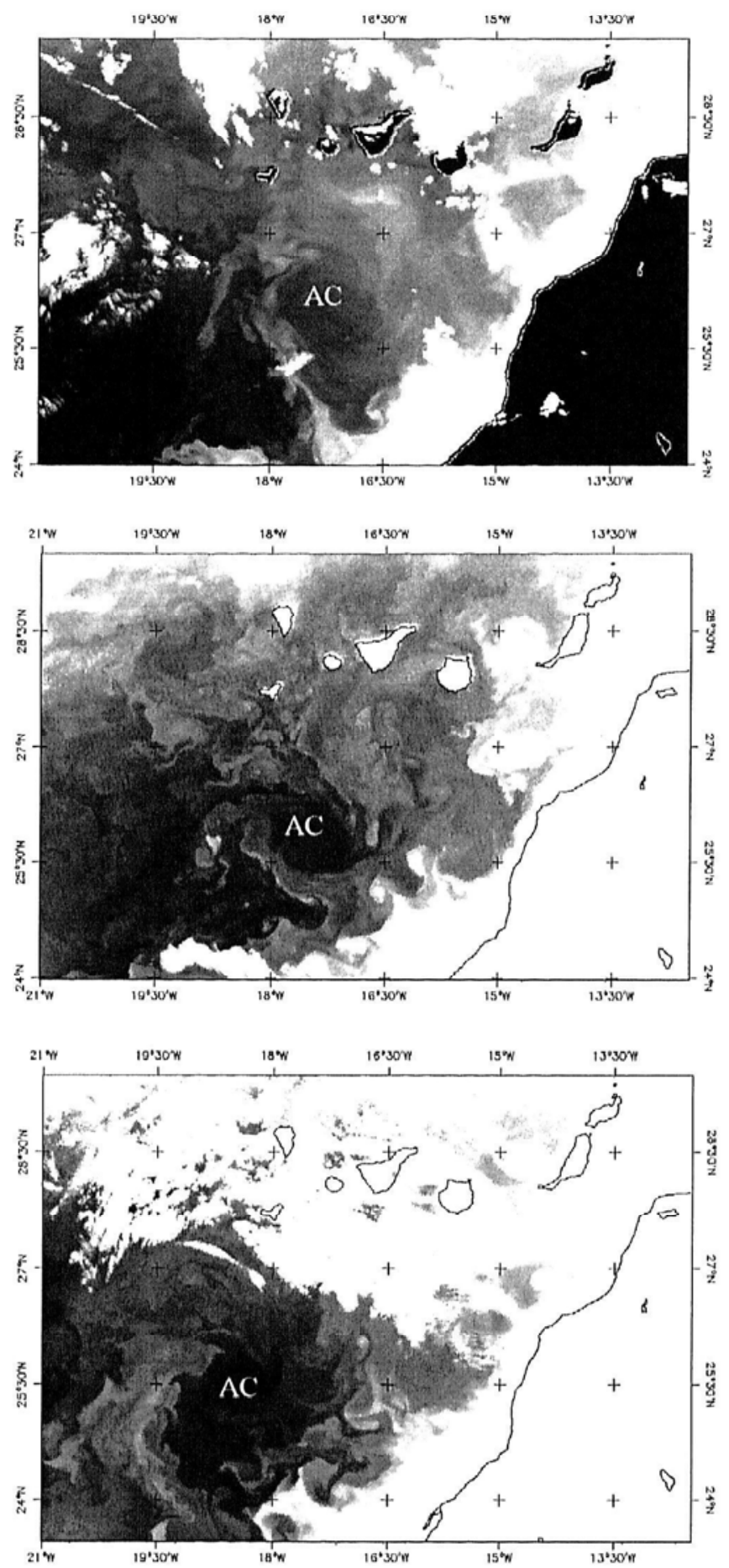

Figure 3.- Infrared satellite images from AVHRR sensor for (a) 1 December 97, (b) 11 December 97 and (c) 17 January 98. 

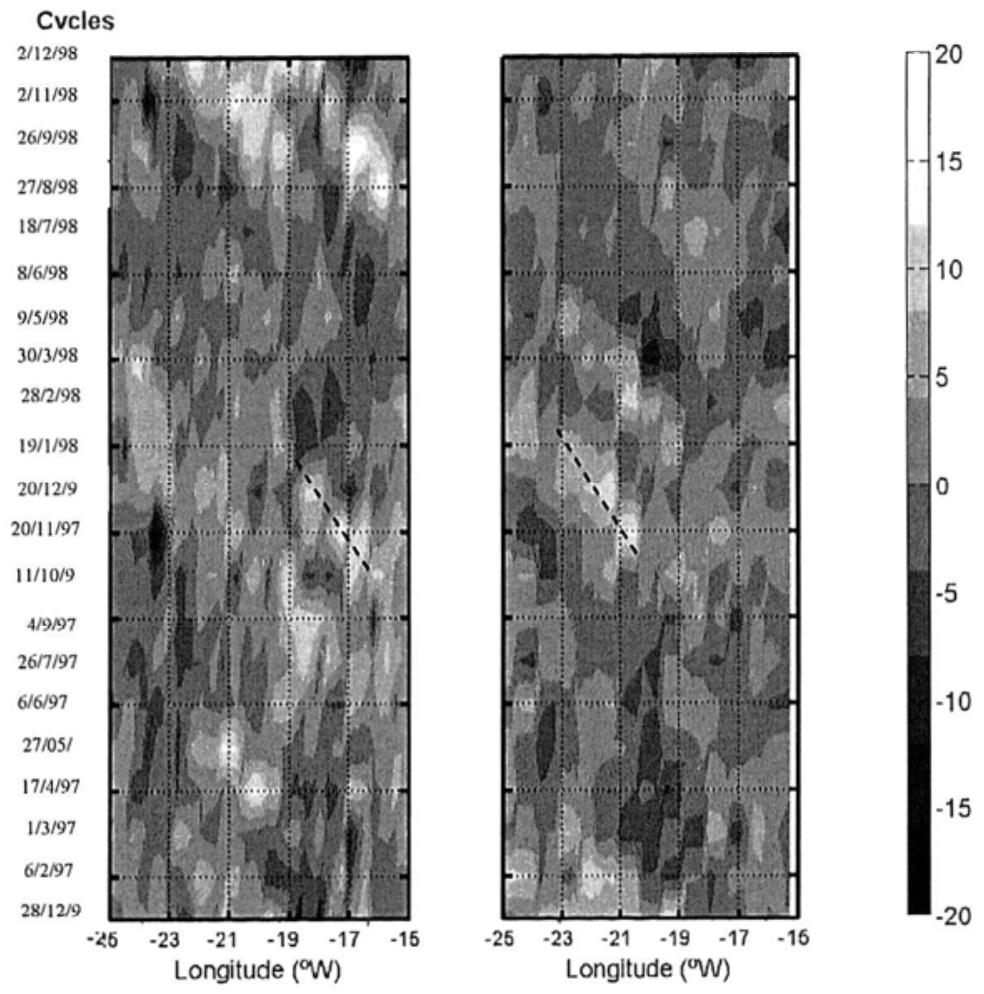

Figure 5.- Hovmöller diagrams of the sea level anomalies at $26^{\circ} \mathrm{N}$ latitude (left) and $25^{\circ} \mathrm{N}$ latitude (right).

\section{CONCLUSIONS}

Anticyclonic eddy has been tracked using data from altimeters on board ERS and TOPEX/Poseidon satellites. A comparison of sea level anomaly derived of altimeter and brightness temperature images indicate an anticyclonic eddy which was detected in October 1997 south of Gomera. The path followed by the anticyclone was at southwestward between November 1997 to January 1998. The translation velocity was of $1.7 \mathrm{~km} /$ day. Track by track analyses show that the eddy was initially detected near Cape Bojador and was advected to open sea. This result suggests that its formation and development is linked to a filament from the upwelling region in Northwest of Africa. This type of feature has been detected by altimetry technique but in summer period (August 1993) (Tejera et al., 2002). Its detection in autumn (November 1997) could indicate that it is recurrent oceanographic mesoscale structure in Canary region. In fact Garcia et al., (2003) has documented using sea surface temperature scenes the recurrence of eddies around Canary Archipelago, that appears mainly in second semester in 1998. Hovmöller diagram has showed anticyclones not only in December 1997; it seems that these positive anomaly cores are also presented in March 1997 and September 1998. They were located at westward El Hierro and at vicinity Cape Bojador $\left(\sim 26^{\circ} \mathrm{N}-16^{\circ} \mathrm{W}\right)$ propagating southwestward.

\section{ACKNOWLEDGMENTS}

The authors thank AVISO Altimetry for provision of the altimeter data. AVHRR images have been acquired by SeaS Canarias (Survey of the Environmental Assisted by Satellite), Biology Department, University of Las Palmas de Gran Canaria. This work was supported by projects UNI99/00, CICYT MAR97-0464-CO4, and REN2000-1503-C0202/MAR. 


\section{REFERENCES}

1. J. Aristegui, P. Sangrá, S. Hernández-León, M. Cantón, A. Hernández-Guerra, and L. Kerling, "Island-induced eddies in the Canary Islands", Deep Sea Research, 41, 1509-1525, 1994

2. J. Arístegui, P. Tett, A. Hernández-Guerra, G. Basterretxea, M:F. Montero, K. Wild, P. Sangrà, S. HernándezLeón, M. Cantón, J.A. Garcia-Braun, and M. Pacheco, "The influenced of island-generated eddies on chlorophyll distribution: a study of mesoscale variation around Gran Canaria". Deep Sea Research, 44, 71-95, 1997

3. AVISO. User Handbook, Sea Level Anomalies (SLAs), AVI-NT-011-312-CN, $3^{\text {rd }}$ Edition, 1998.

4. E.D. Barton, J. Arístegui, P. Tett, M. Cantón, J. García-Braun, S. Hernández-León, L. Nykjaer, C. Almeida, S. Ballesteros, G. Basterretxea, J. Escánez, L. Garcia-Weill, A. Hernández-Guerra, F. López-Laatzen, R. Molina, M.F. Montero, E. Navarro-Pérez, J.M. Rodríguez-Pérez, K. Van Lenning, H. Vélez, and K. Wild, "The Transition Zone of the Canary Current Upwelling Region". Progress in Oceanography, 41, 455-504, 1998.

5. G. Basterretxea, E.D. Barton, , P. Tett, ,P. Sangrà, A. Hernández-Guerra, E. Navarro-Pérez, and J. Aristegui, "Eddy and deep chlorophyll maximum response to wind-shear in the lee of Gran Canaria ". Deep Sea Research Part 1, 49, 1087-1101, 2002

6. L. García-Weil, "Descripción y análisis cuantitativo mediante series de imágenes de satélite de la dinámica de las aguas superficiales del noroeste de Africa". PhD. thesis, Universidad de Las Palmas de Gran Canaria 1998

7. L. García-Weil, L, A. Luque-Söllheim, A. Tejera-Cruz and O. Bergasa-López, "Analysis of Canary Island induced eddies during the 1998 year observed with infrared and altimeter data." Submitted to Deep Sea Research Part 1.

8. K.J. Heywood, E.L. McDongh, and M.A. White, "Eddy kinetic energy of the North Atlantic subpolar gyre from satellite altimetry". Journal of Geophysical Research, 99, 22525-22539, 1994.

9. A. Hernández-Guerra, J. Aristegui, M. Cantón, and L. Nykjaer., "Phytoplankton pigment patterns in the Canary Islands area as determined usin Coastal Zone Colour Scanner data. International Journal of Remote Sensing, 18, 2539-2558, 1993.

10. A. Tejera-Cruz, "Estudio de estructuras oceanográficas mesoescalares en la Cuenca Canaria mediante los altímetros de los satélites GEOSAT, ERS-1 y TOPEX/POSEIDON". PhD. thesis, Universidad de Las Palmas de Gran Canaria., 1996

11. A. Tejera-Cruz, L. García-Weil, L, K.J. Heywood and M. Cantón-Garbin, "Observations of oceanic mesoscale features and variability in the Canary Islands area from ERS-1 altimeter data, satellite infrared imagery and hydrographic measurements", International Journal of Remote Sensing 23, 4897-4916, 2002. 
Figure 4 illustrates the SLA signature along the ascending track 137 of the TOPEX/Poseidon crossing over the AC (see the Fig. 1 where the tracks is marked). The sea surface elevation related to an AC eddy was clearly observed in the marked cycles (Fig. 4 dash lines) corresponded to November and December 1997. Even though images days before the first of December were not available and with the gaps observed in cycle 190 (15.11.97), we are rather confident that the anticyclone was probably present from October 1997. The maximum value showed in individual track 137 located the $\mathrm{AC}$ at south of small island Gomera $\left(26^{\circ} \mathrm{N}\right)$ in cycle 191 (25.11.97), and the peak was moving and smoothing southward disappearing in cycle 196 (14.1.98). The displacement of the AC feature was around $100 \mathrm{~km}$ in forty days. The height of the sea level decreased from $25 \mathrm{~cm}$ registered at the end of November at $26.5^{\circ} \mathrm{N}$ to $15 \mathrm{~cm}$ in February. During this period the vortex is displaced southwest at $1.7 \mathrm{~km} /$ day.

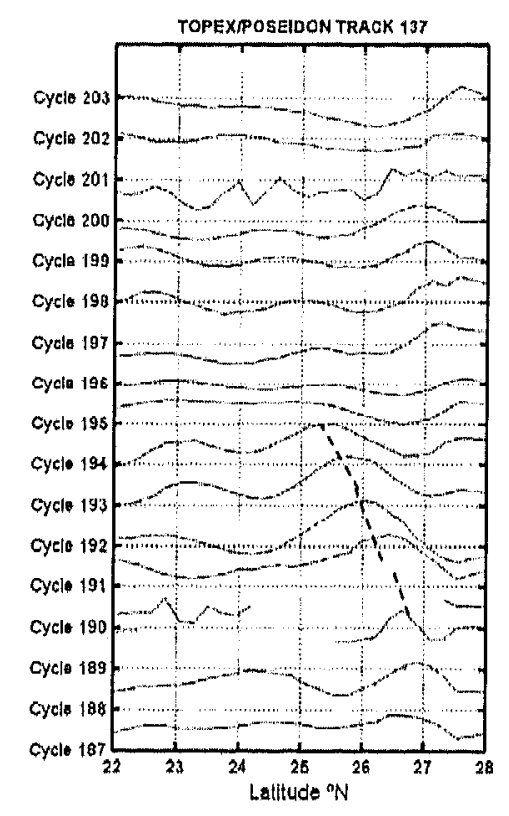

Figure 4.- Ascending TOPEX/Poseidon track sea level anomalies offset from one another $15 \mathrm{~cm}$ for clarity

Also to track the eddy space sea level anomalies from TOPEX/Poseidon and ERS satellite were plotted for $26^{\circ} \mathrm{N}$ and $25 \mathrm{~N}$ (Fig. 5). The Y-axis represents altimeter cycles where 018 correspond to first of the 1997 and also of 038 of 1999 years, respectively. High mesoscale activity is shown in the region. As it has been mentioned above maximum variations of the sea level anomalies was registered at south of Gomera (AC) in December 1997 moving from $16^{\circ} \mathrm{W}$ to $19^{\circ} \mathrm{W}$ (Fig. 4a). However it could be identified others individual eddy presented next to the African coast, near Cape Bojador ( $~$ $26^{\circ} \mathrm{N}-16^{\circ} \mathrm{W}$ ) (cycle 25 and 36, September 1997 and October 1998, respectively). Meanwhile at $25^{\circ} \mathrm{N}$ (Fig. 5b) the vortex $\mathrm{AC}$ has been detected again and the altimetric signal is decreased until $23^{\circ} \mathrm{W}$. 